\title{
تحديث العربية ومستقبلها في سوق لغات العالم الجلس الأعلى للغة العربية بالجزائر
}

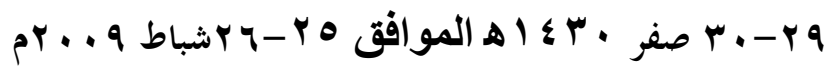

* وليد العناتي

نظم الجحلس الأعلى للغة العربية بالجمهورية الجزائرية ندوة دولية احتفاءً بالذكرى

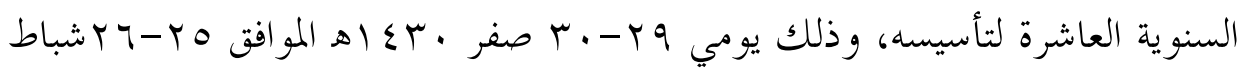

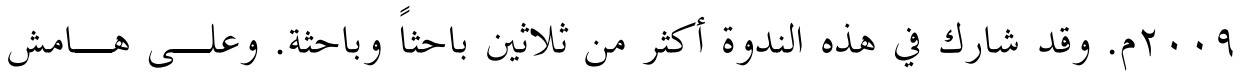

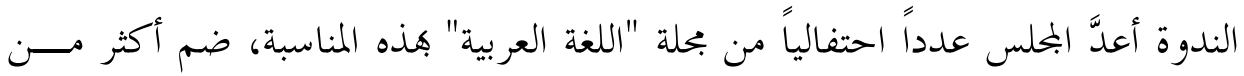

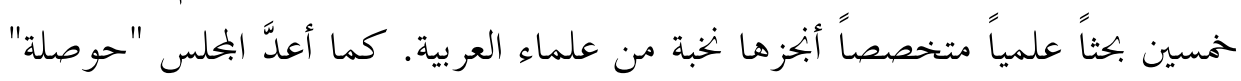

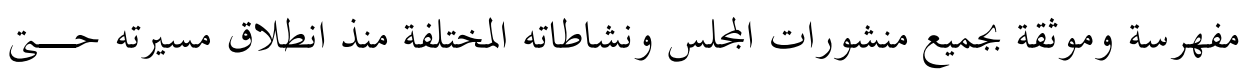
موعد هذه الندوة.

بدأت فعاليات المؤتمر بالجلسة الافتتاحية، التي تحدث فيها الدكتور محمد العــربي

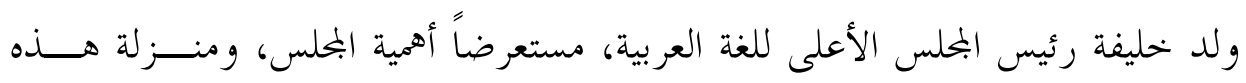

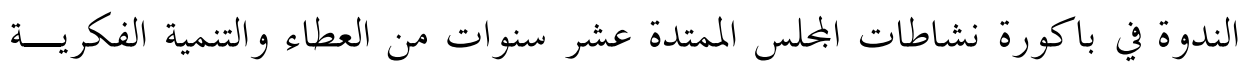
و الثقافية. كما تحدث وزير الدولة السيد عبد العزيز بلخادم عن رؤية رئاسة الجمهورية لرسالة اللغة العربية في توطين التعريب، وتعزيز الهوية العربية الإسلامية للجزائر.

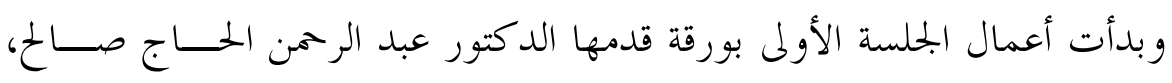

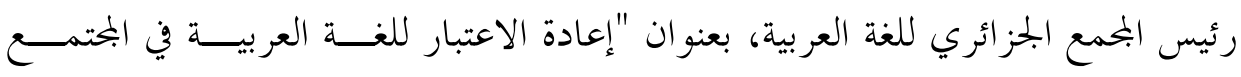

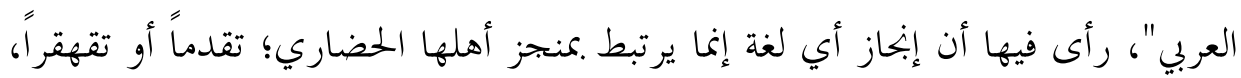

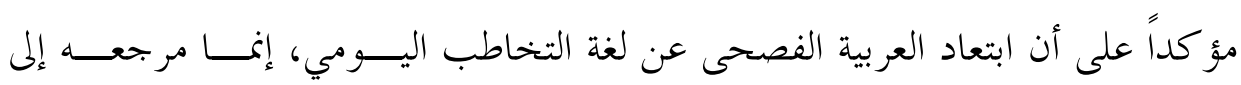
الجمود الفكري وضآلة الإنتاج المعرفي في الوطن العربي. 
وقدم الوزير الجزائري الدكتور بوعبد الله غلام الله ورقة بعنوان "مستقبل اللغــة فئة

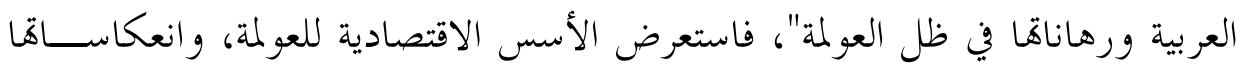

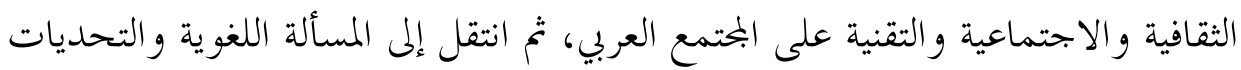
التي تواجهها العربية في العالم، و كيفية تحصينها لمواجهة هذه التحديات لتحمل رسالتها العالمية، ولتعود لغة عالمية من جديد. واستعرض الأستاذ علي القاسمي من مكتب تنسيق

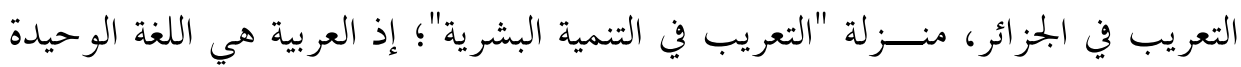

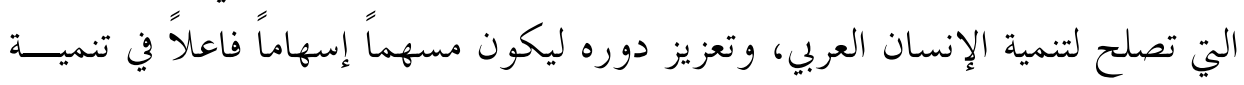
محتمعه ورَقِيِّه.

وقدم الدكتور يعقوب الشّرّاح من مركز تعريب العلوم الصحية في الكويت، ورقة

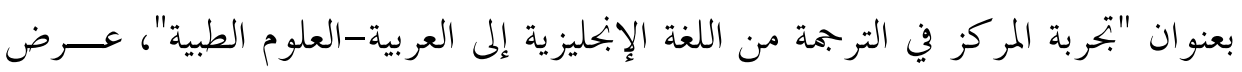

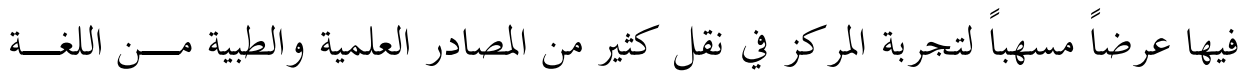

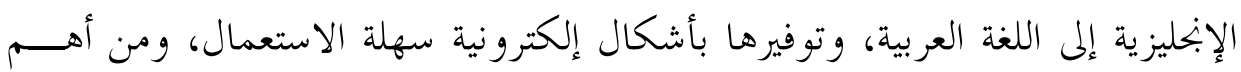

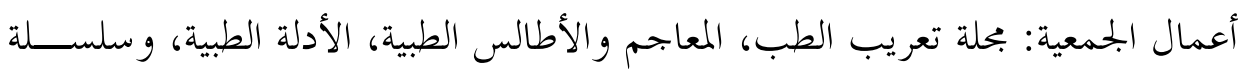

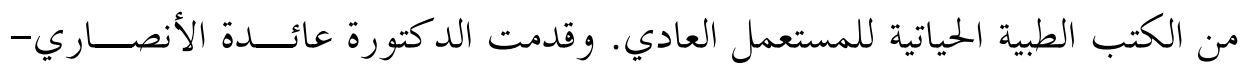

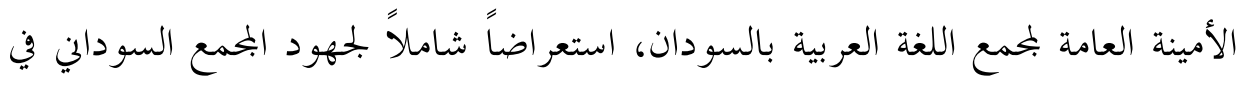
دعم اللغة العربية، من حيث نشر المصطلحات وتوحيدها، وتعريب التعليم، وإصــــار بحلة علمية محكمة تعنى بقضايا العربية المعاصرة.

و لم تغب فكرة عالمية اللغة العربية عن وقائع الندوة؛ ففي الجلسة الثانية من اليــوم

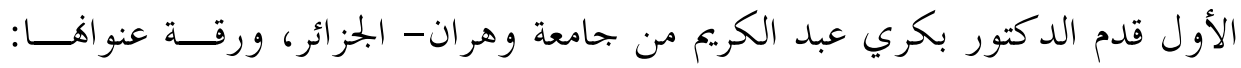

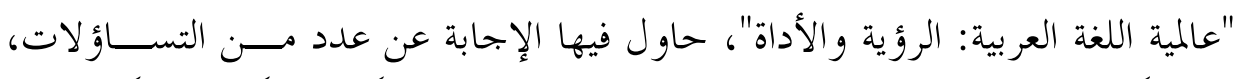

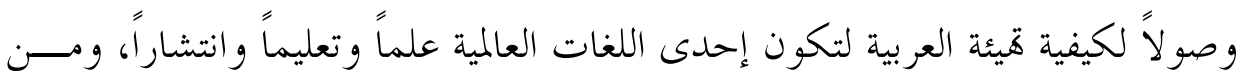

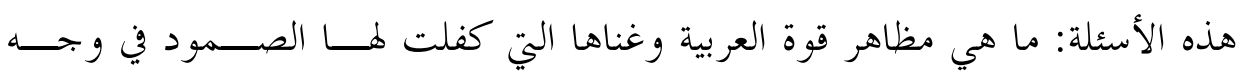

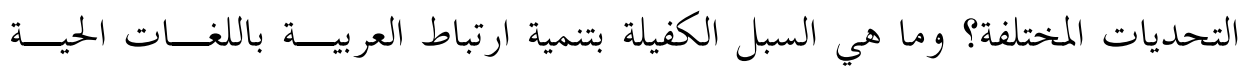

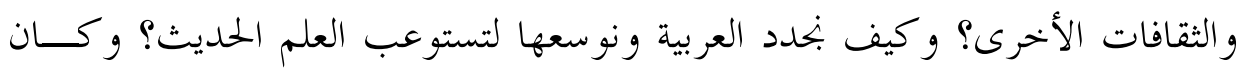

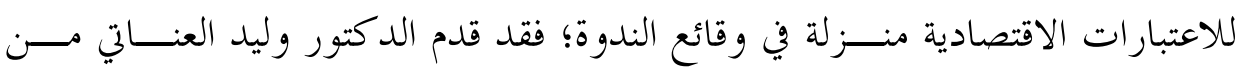




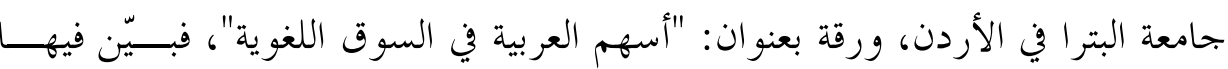

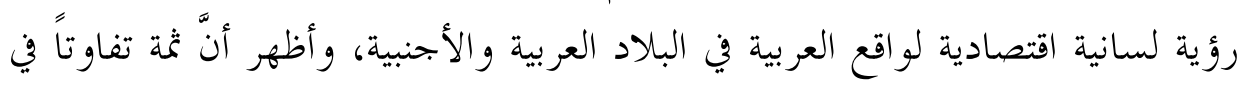

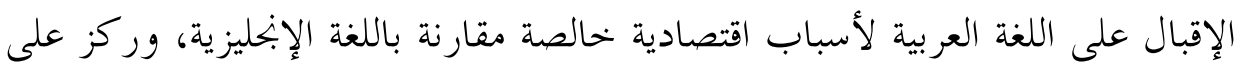

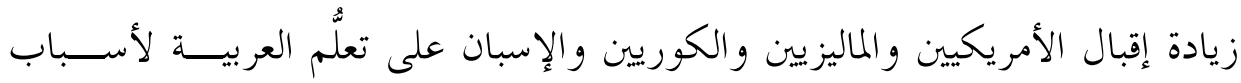
متفاوتة؛ فمنه ما هو سياسي وآخر ثقافي وآخر اقتصادي.

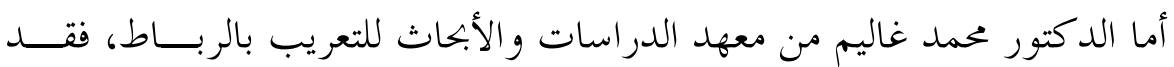

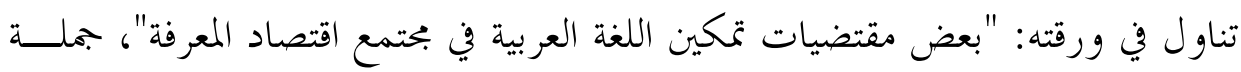

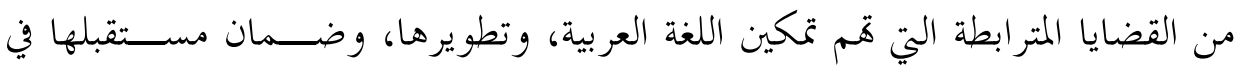

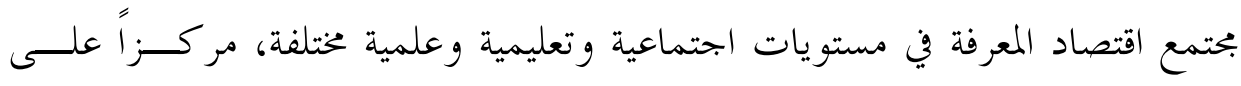

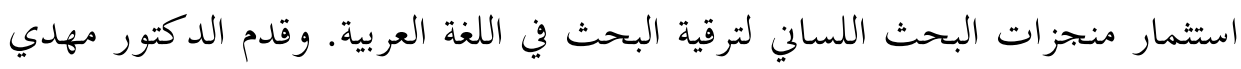

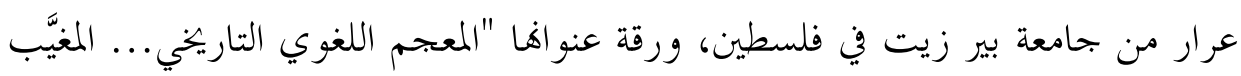

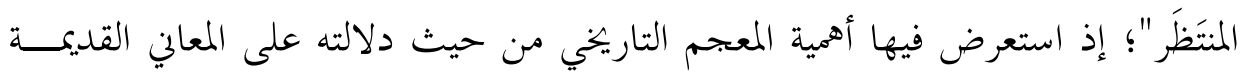

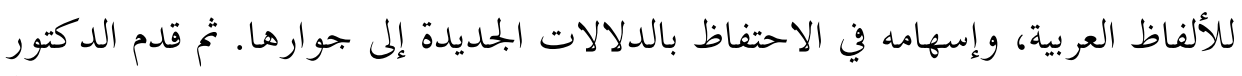

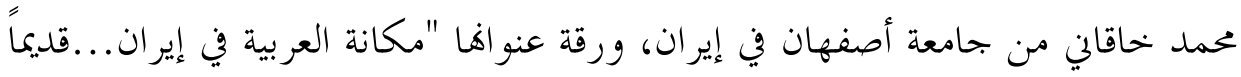

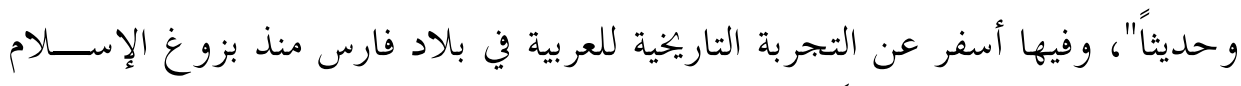

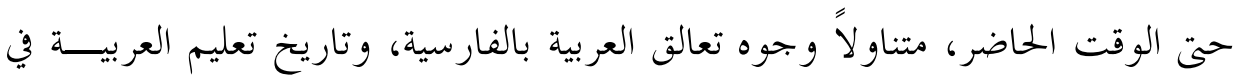
إيران، ومؤسسات تعليم العربية فيها.

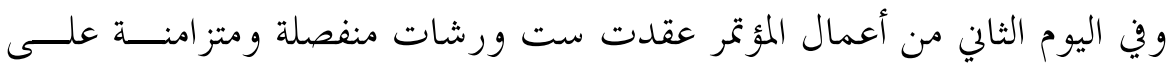

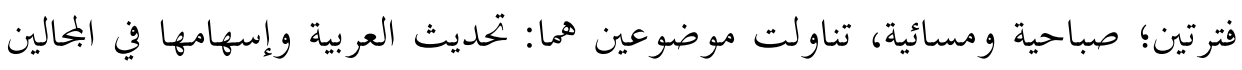
العلمي والتكنولوجي. ومستقبل العربية في سوق اللغات.

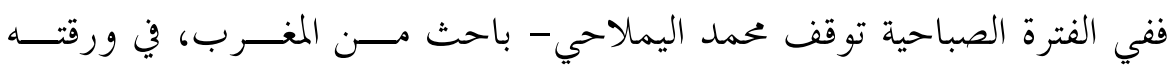
"بحليات الثقافة العربية في الصناعة المعجمية"، عند أثر الثقافة العربية في صناحثة الثباعة المعاجم،

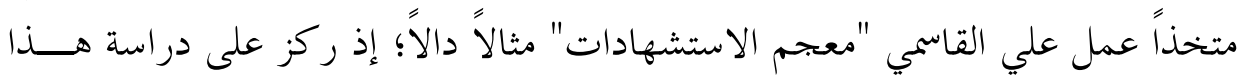

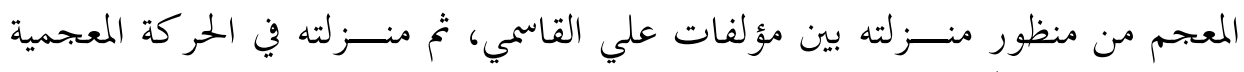

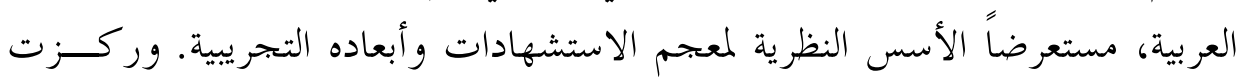


ورقة الدكتور رشيد بن مالك، مدير مركز البحث العلمي والتقين لتطوير اللغة العربية

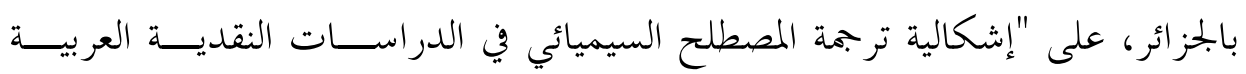

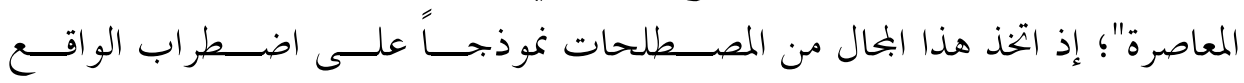
الاصطلاحي العربي، و تعدد إشكالاته، وغياب التنسيق، وما يترتب على ذلك من هدر للطاقة والوقت. وقدّم الدكتور عبد القادر فضيل - باحث في علوم التربية- الجزائر، ورقة بعنـــوان

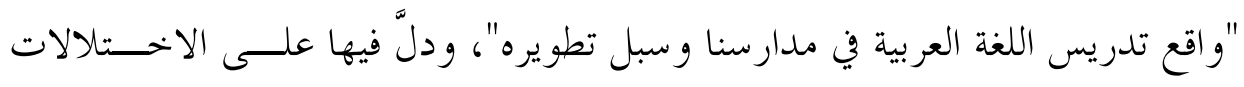

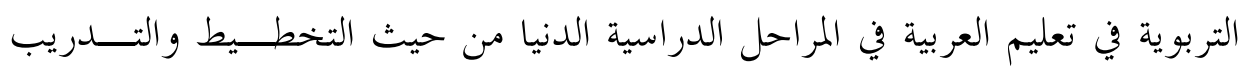
و التنفيذ؛ إذ توقف عند كثير من الممارسات الحناطئة في تعليم العربية وإعداد مقرر اهاها،

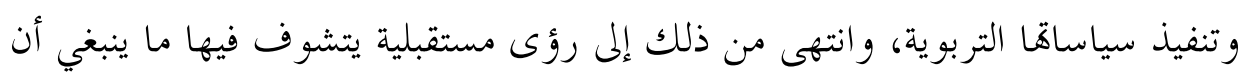
يكون عليه تعليم العربية لأبنائها في هذه المرحلة التأسيسية.

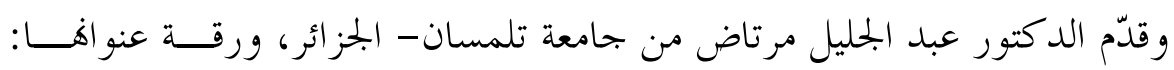

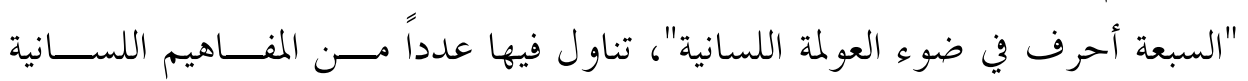

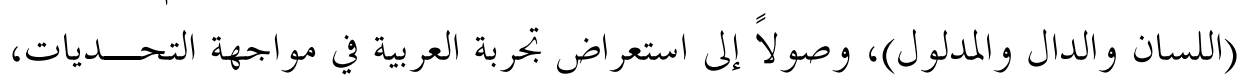

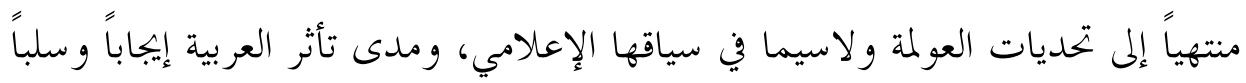

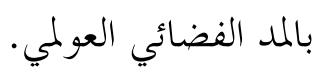
أما الدكتور أحمد بوطرفاية- رئيس جامعة وَرْقَلة- الجزائر، فقد تناول في ورقتــهـ

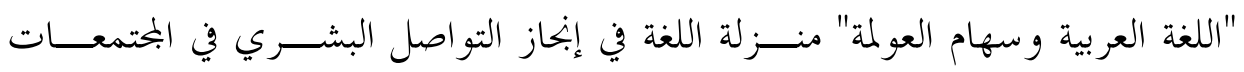

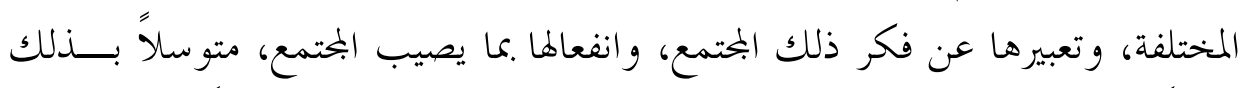

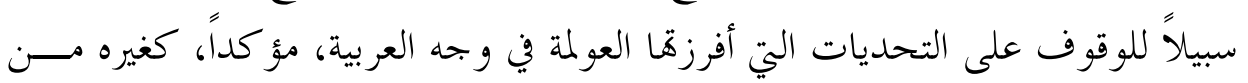

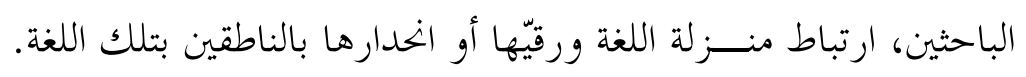

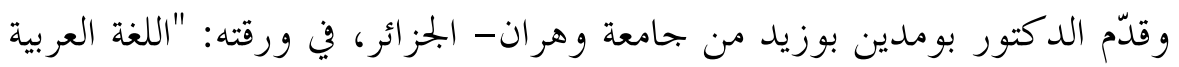

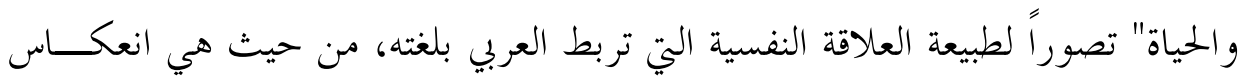

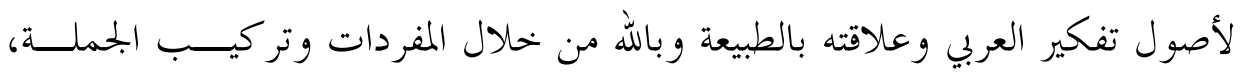
و كيفية تطور ذلك في عصور ازدهار الحضارة العربية الإسلامية. 


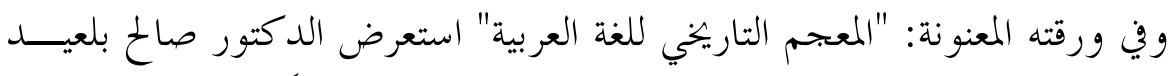

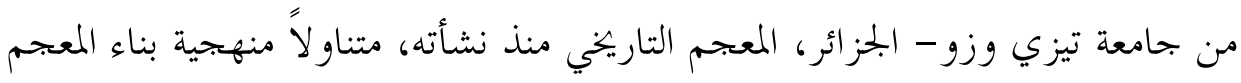

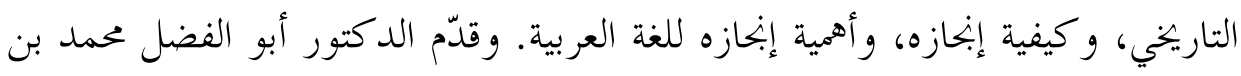

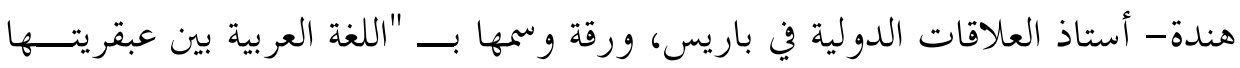

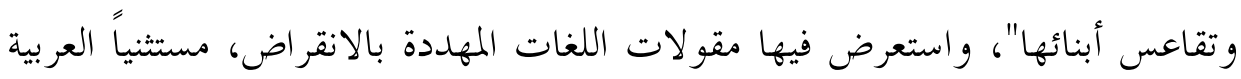

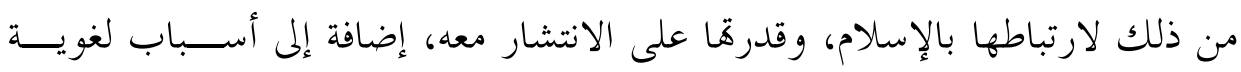

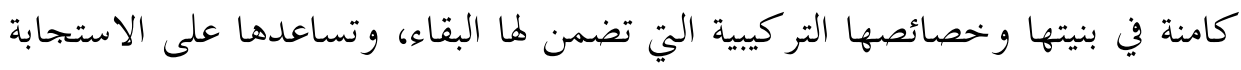

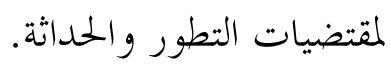

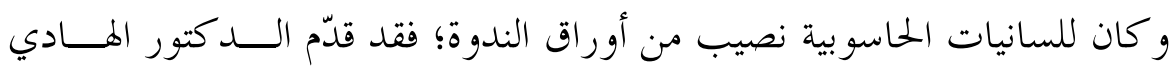

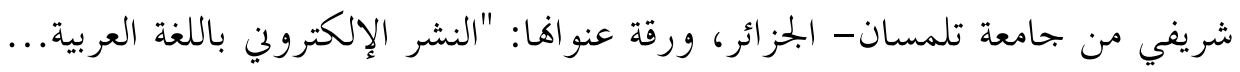

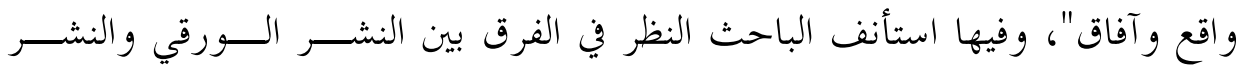

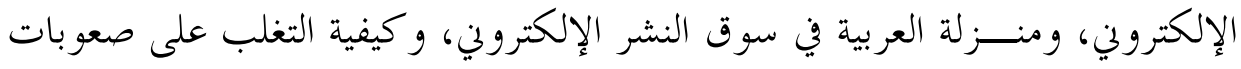

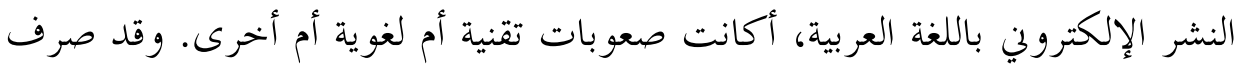

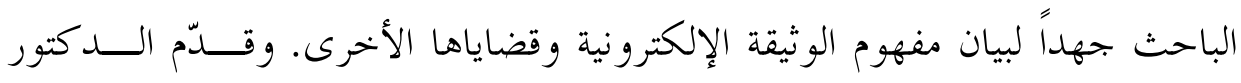

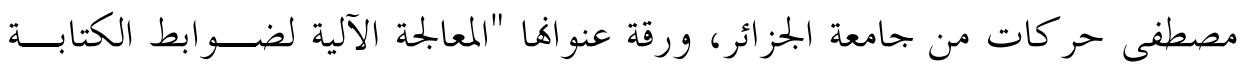

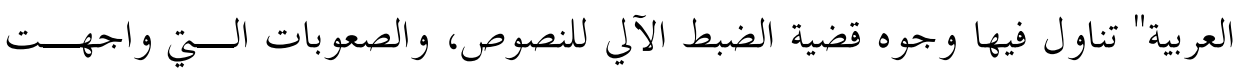

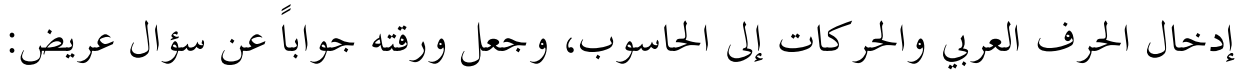
لماذا نضبط النصوص العربية؟

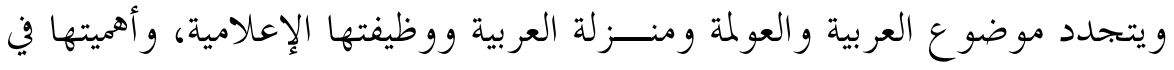

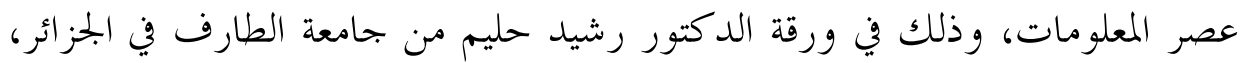

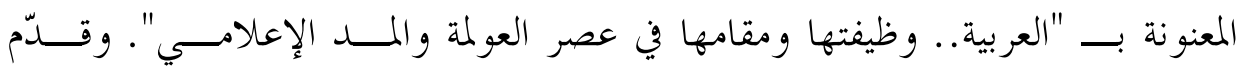

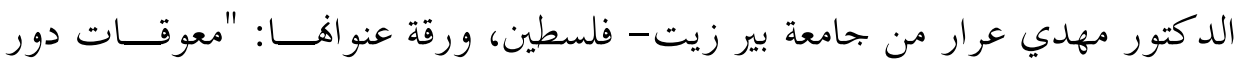

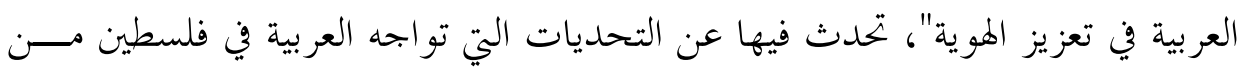

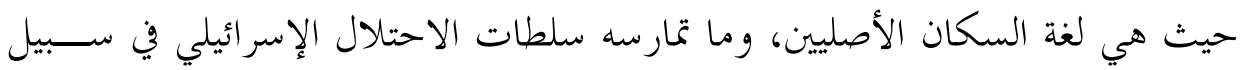
هويد اللغة والميط. 
وقُدّمت في الجلسة المسائية خمس أوراق، استهلها الدكتور محمد ناصر بوحَجَّــام

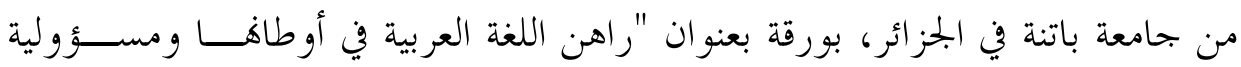

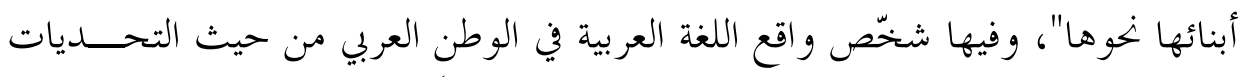

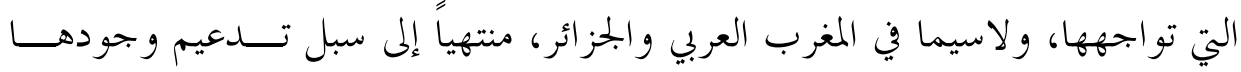

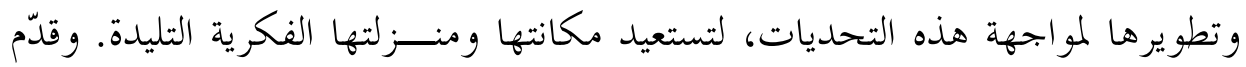

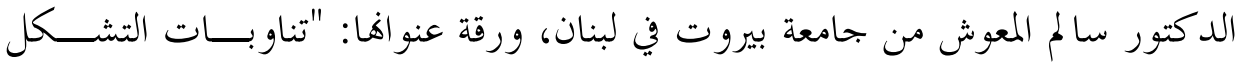
و اللاتشكل على اللغة العربية"، استنفد فيها القدرات الكامنة في العربية التي بتعلها قابلة

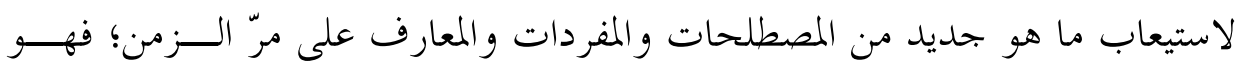

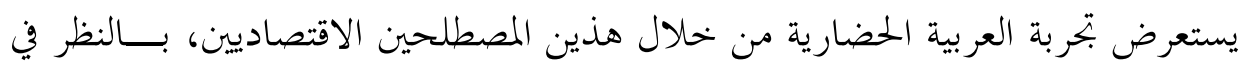

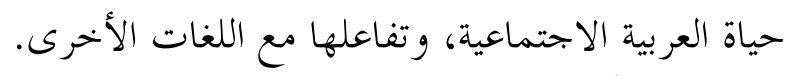

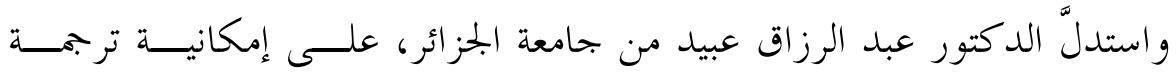

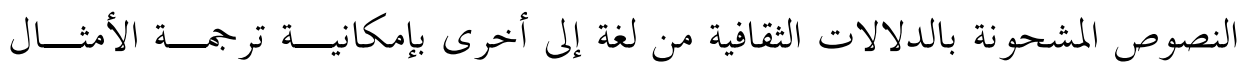
و الحكم؛ وذلك في ورقته: "ترجمة الأمثال و الحكم من اللغة الفرنسية إلى اللغة العربية: المشاكل والحلول". و وتناول الدكتور محمد الينبعي من جامعة فاس في المغرب، في ورقته ورته "اللغة العربية في أوطاها بين تحدياها و آفاقها"، التحديات الإعلامية و التعليمية والإدارية

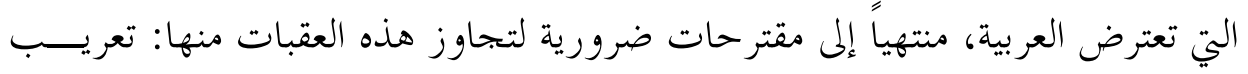
الخحيط، وتطوير المناهج، وتفعيل دور البحامع اللغوية. وعاد الدكتور محمد خاقاني ليقدم استعر اضاً لتاريخ اللغة العربية في إيران تعليماً وتعلماً.

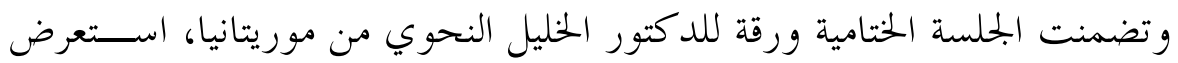

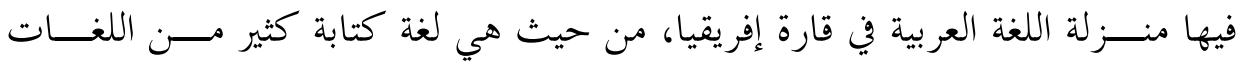
الإفريقية، ولها علاقات وثيقة بلغات القارة. وأكد ضرورة استثمار هذه العلاقة لتمكين

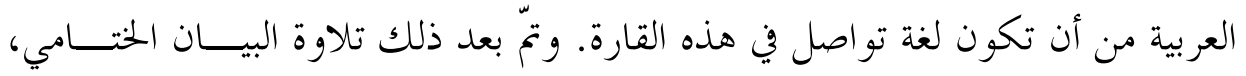
و التوصيات، وأبرز ما جاء فيها:

ا ـ دعوة الدول العربية إلى التخاذ قرار ملزم باستخدام اللغـــة العربيــة في كــل

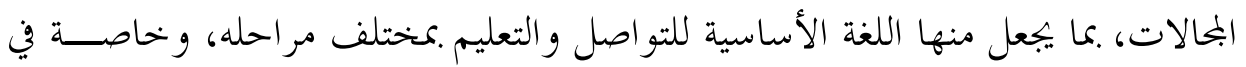




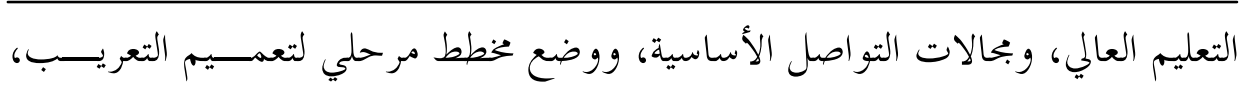

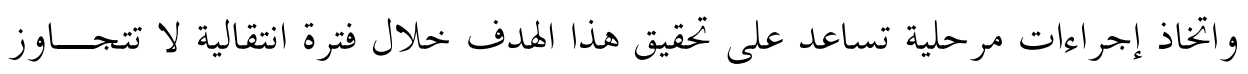
عشر سنوات.

r. دعوة الدول العربية والمنظمات و الهيئات والاتحادات القطرية و القوميــة، وفي

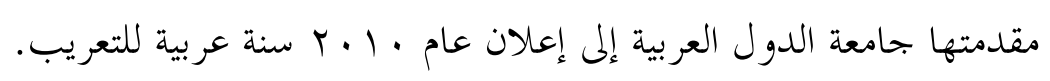

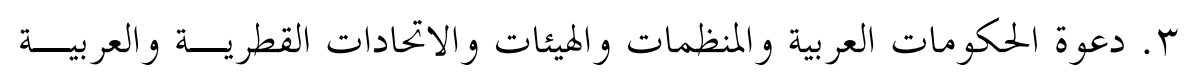

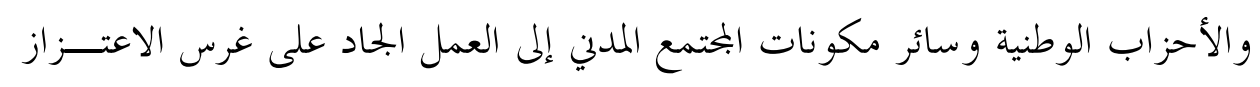

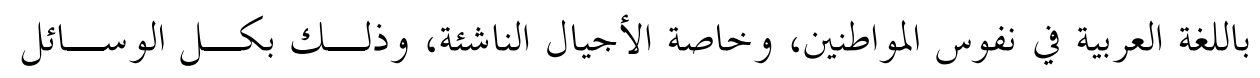

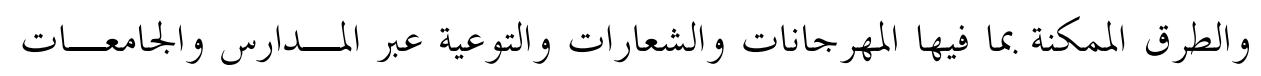
وو سائل الإعلام و ونو ادي الشباب و الثقافة.

ع. دعوة الجامعات ومراكز البحوث إلى مزيد من العناية باللسانيات الحاســـوبية

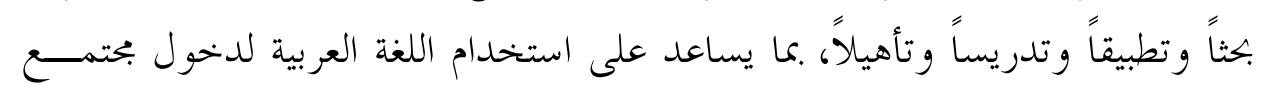
المعرفة وتحقيق التنمية البشرية.

هـ دعم الجهود التي تبذها البحامع و المنظمة العربيــة للتربيـــة والثقافــة و العلـــوم

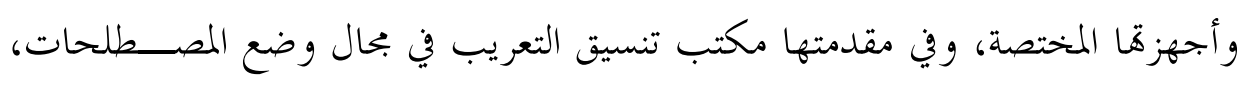
وتو حيدها، و وتقييسها، وإشاعتها.

7. دعوة الجامعات، ومراكز البحوث، و المنظمات، والهيئات الوطنية والقومية إلى له

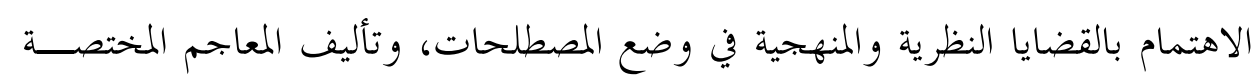
و العامة.

V. العمل باستمرار على تطوير طرائق وأساليب تدريس اللغة العربية في التعلــيم

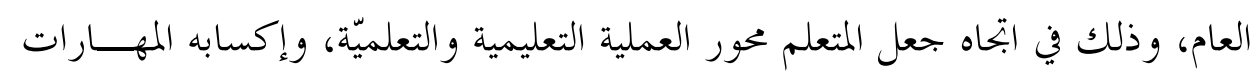

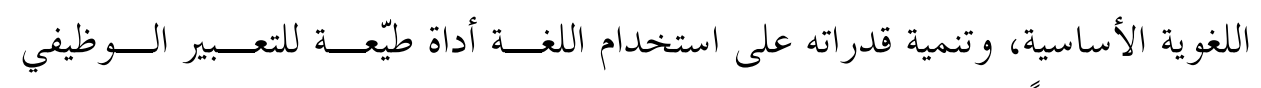
و الإبداعي تحدثاً وكتابة. 
^. الدعوة إلى إنشاء بحلس أعلى للغة العربية لدى جامعة الدول العربية، لتنســيق سياسات الأقطار العربية وجهودها في النهوض باللغاء بكس العيل العربية.

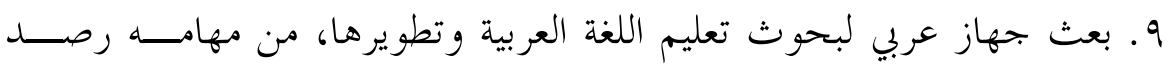

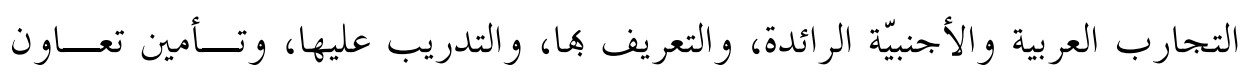
تربوي وعلمي فعّال بين الأقطار العربية في بحال تدريس اللغة العربية. • ا ـ زيادة الاهتمام بالترجمة العلمية و التكنولوجية، بما يسدّ حاجات الجامعــات، وقطاعات الإنتاج من الكتب المرجعية والتعليمية اللازمة.

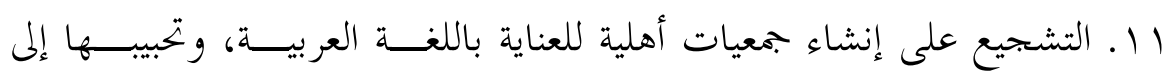
المو اطنين و الناشئة.

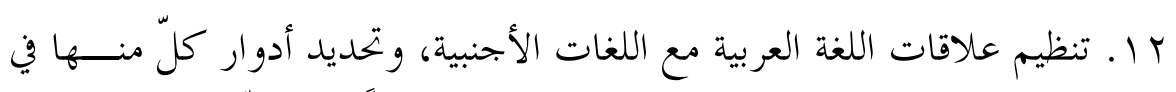

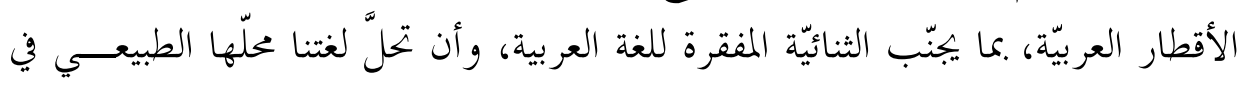

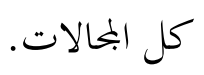

با ـ فرض اللغة العربية في المدارس الخاصة بجصص ومقررات كافية لإكســاب المتعلمين مهارات اللغة العربية، ولتأمين تعلّقهم بها. ع ا ـ دعوة الجهات الوطنيّة والإقليمية المعنيّة -ووفي مقدّمتها الجحامعات والمنظمـــة

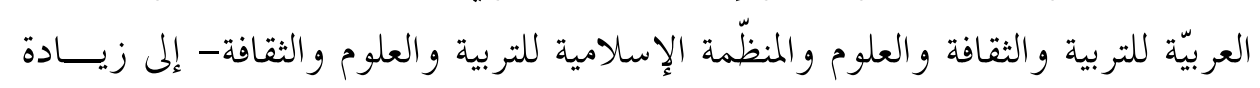

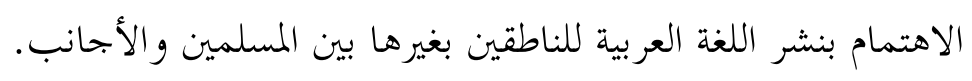

